\title{
Large second-harmonic generation in thermally poled silica waveguides
}

\author{
Arentoft, Jesper; Kristensen, Martin; Pedersen, K.; Bozhevolnyi, S.I.; Shi, Peixiong
}

Published in:

Proceedings on Optical Fiber Communication Conference and Exhibit

Link to article, DOI:

10.1109/OFC.2001.927835

Publication date:

2001

Document Version

Publisher's PDF, also known as Version of record

Link back to DTU Orbit

Citation (APA):

Arentoft, J., Kristensen, M., Pedersen, K., Bozhevolnyi, S. I., \& Shi, P. (2001). Large second-harmonic generation in thermally poled silica waveguides. In Proceedings on Optical Fiber Communication Conference and Exhibit (Vol. 1) https://doi.org/10.1109/OFC.2001.927835

\section{General rights}

Copyright and moral rights for the publications made accessible in the public portal are retained by the authors and/or other copyright owners and it is a condition of accessing publications that users recognise and abide by the legal requirements associated with these rights.

- Users may download and print one copy of any publication from the public portal for the purpose of private study or research.

- You may not further distribute the material or use it for any profit-making activity or commercial gain

- You may freely distribute the URL identifying the publication in the public portal

If you believe that this document breaches copyright please contact us providing details, and we will remove access to the work immediately and investigate your claim. 


\title{
Large second-harmonic generation in thermally poled silica waveguides
}

\author{
J. Arentoft and M. Kristensen \\ Research Center COM, Technical University of Denmark, Building 345 west, DK-2800 Kgs. Lyngby, DENMARK \\ Tel: +454525 3772, Fax: +45 4593 6581, E-mail: ja@com.dtu.dk, mk@com.dtu.dk \\ K. Pedersen and S.I. Bozhevolnyi \\ Institute of Physics, Aalborg University, Pontoppidanstrade 103, DK-9220 Aalborg, DENMARK \\ P. Shi \\ Mikroelektronik Centret, Technical University of Denmark, Building 345 east, DK-2800 Kgs. Lyngby, DENMARK
}

\begin{abstract}
We report the observation of very large second-harmonic signals from thermally poled silica waveguide samples. Secondary Ion Mass Spectrometry measurements show that significant amounts of silver ions are injected from the top electrode during poling.

(C)2000 Optical Society of America

OCIS codes: (190.4160) Multiharmonic generation, (190.4390) Nonlinear optics, integrated optics
\end{abstract}

\section{Introduction}

Active nonlinear optical devices based on poled silica [1] would offer an attractive alternative to expensive nonlinear crystals, such as $\mathrm{LiNbO}_{3}$. In this work we present new results indicating that poling of silica waveguides gives nonlinear coefficients within $30 \%$ of those for $\mathrm{LiNbO}_{3}$. To the best of our knowledge the results represent a world record for poling of silica-based waveguides.

\section{Sample preparation}

Silica-based channel waveguides (see Fig.1) were produced with Plasma Enhanced Chemical Vapor Deposition (PECVD) and subsequent UV-writing [2]. A silver-containing paint was used as top electrode while the silicon wafer was used as bottom electrode. One sample was (positively) poled by applying $+1 \mathrm{kV}$ to the top electrode at $430^{\circ} \mathrm{C}$.

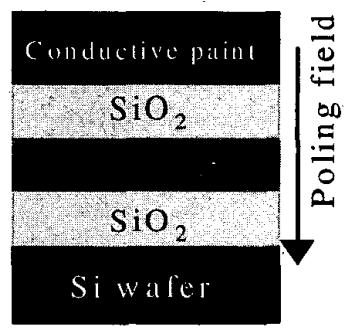

Fig. 1. Sample grown by PECVD with top electrode of conducting silver paint. Field direction indicated for positive poling.

Another sample was (negatively) poled using $\div 1 \mathrm{kV}$. The samples were both poled for 25 minutes and then cooled to room temperature with the voltage still on. After poling, the samples were cleaved through the poled area and the distribution of the second-order nonlinearity (SON) along the coordinate parallel to the poling field was investigated.

\section{Optical characterization}

A $755 \pm 7 \mathrm{~nm}$ pump beam (spot size $2 \mu \mathrm{m}$ ) with normal incidence was scanned across the glass layers in steps of 0.25 $\mu \mathrm{m}$ and the reflected second-harmonic (SHG) signal was recorded. One of the recorded profiles is shown in Fig. 2. 


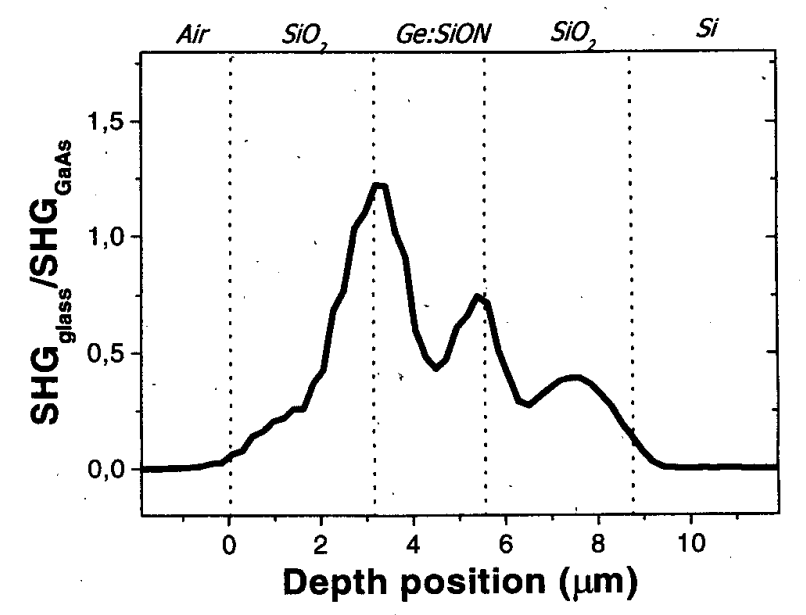

Fig. 2. SHG depth profile of positively poled waveguide sample.

The setup was calibrated by measuring the SHG from the (311) surface of GaAs under the same experimental conditions. For the positively poled sample the peak value of $\chi^{(2)}(-2 \omega ; \omega, \omega)$ is estimated to be $22 \pm 8 \mathrm{pm} / \mathrm{V}$, while the peak value for the negatively poled sample was $0.6 \pm 0.2 \mathrm{pm} / \mathrm{V}$. These estimations are based on the formalism developed by Bloembergen [3] and the measurements of $\chi^{(2)}(-2 \omega ; \omega, \omega)$ for GaAs reported in reference [4]. In contrast to the large SHG signal, only small linear electro-optic (LEO) effects were detected in the channel waveguides of the positively poled sample. The negatively poled sample showed a LEO coefficient of $\chi^{(2)}(-\omega ; \omega, 0)=$ $0.05 \mathrm{pm} / \mathrm{V}$.

\section{Poling induced ion migration}

Secondary Ion Mass Spectrometry (SIMS) measurements show that large amounts of positive ions enter the positively poled sample during poling, as illustrated in Fig. 3. In particular, silver (Ag) is present in high concentration, with a peak at the lower core/cladding interface corresponding to 30 atomic \%. For the negatively poled sample we observe no ion migration.

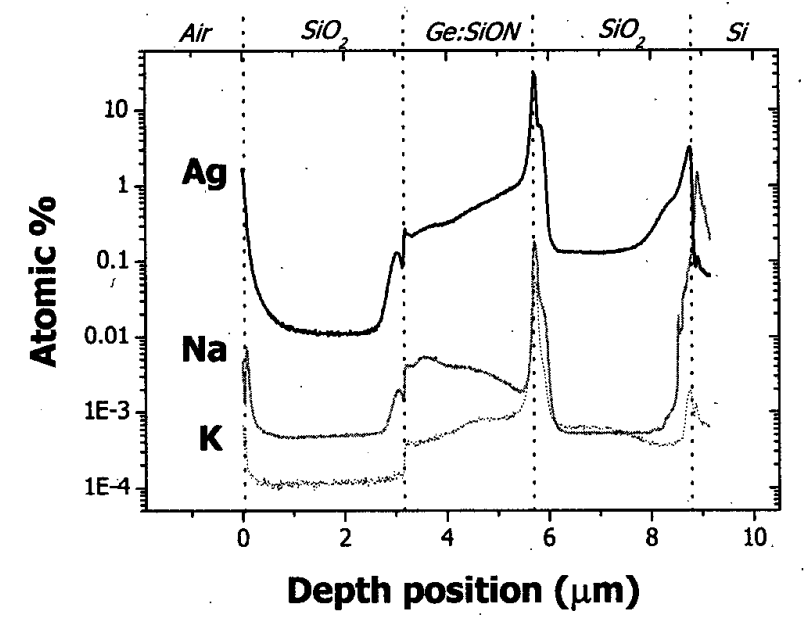

Fig. 3. SIMS concentration depth profiles for the positively poled sample. 


\section{Conclusion}

We believe that the high SON is related to the injection of silver. It is known that silica containing silver nano-scale clusters can exhibit extremely large resonant nonlinear optical effects [5,6]. Comparison of many SHG depths profiles and SIMS concentration profiles, however, did not reveal a simple consistent correlation between the $\mathrm{Ag}$ concentration and the level of SHG. One may speculate that the effect is due to a combination of a large $\chi^{(3)}$ from the silver and an internal electric field resulting from the inhomogeneous ion concentration profiles.

\section{References}

[1] R.A. Myers, N. Mukherjee and S.R.J. Brueck, "Large second-order nonlinearity in poled fused silica", Opt. Lett. 16 (22), $1732-1734$ (1991). [2] M. Svalgaard, C.V. Poulsen, A. Bjarklev and O. Poulsen, "Direct UV writing of buried single-mode channel waveguides in Ge-doped silica films", Electron. Lett. 30 (17), 1401-1403 (1994).

[3] N. Bloembergen and P.S. Pershan, "Light waves at the boundary of nonlinear media", Phys. Rev, 128 (2), 606-6.22 (1962).

[4] R.K. Chang, J. Ducuing and N. Bloembergen, "Dispersion of the optical nonlinearity in semiconductors", Phys. Rev. Lett. 15 (9), $415-419$ (1965).

[5] D. Ila, E.K. Williams, S. Sarkisov, C.C. Smith, D.B. Poker and D.K. Hensley, "Formation of metallic nanoclusters in silica by ion implantation", Nucl. Instr. and Meth. in Phys. Res. B 141, 289-293 (1998).

[6] D. Ricard, Ph. Roussignol and Chr. Flytzanis, "Surface-mediated enhancement of optical phase conjugation in metal colloids", Opt. Lett. 10 (10), 511-513 (1985). 